\title{
Aldol Condensation of Cyclopentanone with Valeraldehyde Over Metal Oxides
}

\author{
Päivi Mäki-Arvela ${ }^{1}$. Nataliya Shcherban ${ }^{1,2} \cdot$ Chloé Lozachmeur $^{1} \cdot$ Kari Eränen $^{1} \cdot$ Atte Aho $^{1} \cdot$ Annika Smeds $^{1}$. \\ Narendra Kumar ${ }^{1} \cdot$ Janne Peltonen ${ }^{3} \cdot$ Markus Peurla $^{4} \cdot$ Vincenzo Russo $^{5} \cdot$ Konstantin P. Volcho $^{6,7} \cdot$ Dmitry Yu. Murzin ${ }^{1}$
}

Received: 20 December 2018 / Accepted: 30 January 2019 / Published online: 20 February 2019

(c) The Author(s) 2019

\begin{abstract}
Kinetics of the cross aldol condensation of valeraldehyde with cyclopentanone was investigated in a batch reactor under atmospheric pressure at $130{ }^{\circ} \mathrm{C}$ using heterogeneous metal modified oxides, such as $\mathrm{CeO}_{2}-\mathrm{MgO}, \mathrm{FeO}-\mathrm{MgO}, \mathrm{FeO}-\mathrm{CaO}$ as well as pristine $\mathrm{CaO}$ as catalysts. The catalysts were prepared either by evaporation impregnation or deposition precipitation methods and characterized by XRD, TEM, SEM, nitrogen adsorption, ammonia and $\mathrm{CO}_{2} \mathrm{TPD}$. The results revealed that an optimum amount of strong basic sites gives the highest ratio between cross condensation and self-condensation products of valeraldehyde. The highest yield of the desired product 2-pentylidenecyclopentanone (66\%) was obtained with $\mathrm{FeO}-\mathrm{MgO}$ prepared by the deposition precipitation methods.
\end{abstract}

\section{Graphical Abstract}

Cross-condensation of valeraldehyde with cyclopentanone was investigated over heterogeneous $\mathrm{Fe}-\mathrm{CaO}, \mathrm{CeO}-\mathrm{MgO}, \mathrm{FeO}-$ $\mathrm{CaO}$ and $\mathrm{CaO}$ catalysts at $130{ }^{\circ} \mathrm{C}$ using cyclopentanone as a solvent and reactant. The highest yield of the desired product, 2-pentylidene-cyclopentanone, finding applications as fragrances, flavours and pharmaceuticals, was $66 \%$ obtained over $\mathrm{FeO}-\mathrm{MgO}$ catalyst exhibiting both acid and basic sites.

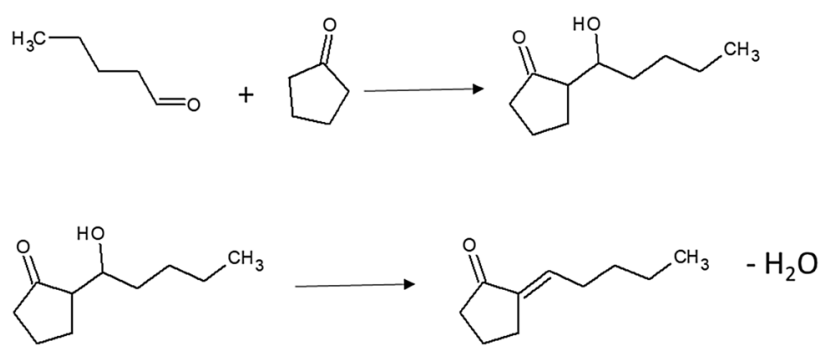

Keywords Basic catalyst $\cdot$ Aldol condensation $\cdot$ Valeraldehyde

Electronic supplementary material The online version of this article (https://doi.org/10.1007/s10562-019-02701-1) contains supplementary material, which is available to authorized users.

Dmitry Yu. Murzin

dmurzin@abo.fi

1 Johan Gadolin Process Chemistry Centre, Åbo Akademi University, Turku, Finland

2 L.V. Pisarzhevsky Institute of Physical Chemistry, National Academy of Sciences of Ukraine, 31 pr. Nauky, Kiev 03028, Ukraine

3 Laboratory of Industrial Physics, University of Turku, Turku, Finland
4 Laboratory of Electron Microscopy, University of Turku, Turku, Finland

5 Università di Napoli Federico II, via Cintia, 4, 80126 Napoli, Italy

6 N. N. Vorozhtsov Institute of Organic Chemistry, Russian Academy of Sciences, Novosibirsk 630090, Russia

7 Novosibirsk State University, Novosibirsk 630090, Russia 


\section{List of symbols}

$K^{0} \quad$ Equilibrium constant at standard conditions for reaction $j$

$n \quad$ Moles, mol

$P \quad$ Pressure, bar

$P^{0} \quad$ Standard pressure, bar

$R \quad$ Ideal gas constant, $\mathrm{J} / \mathrm{K} / \mathrm{mol}$

$T \quad$ Absolute temperature, $\mathrm{K}$

$T^{0} \quad$ Absolute standard temperature, $\mathrm{K}$

\section{Greek symbols}

$\Delta G_{f}^{0} \quad$ Gibbs free energy of formation at standard conditions, $\mathrm{J} / \mathrm{mol}$

$\Delta G^{0}{ }_{r} \quad$ Gibbs free energy of reaction at standard conditions, $\mathrm{J} / \mathrm{mol}$

$\Delta G_{r, j}^{\Phi}$ Gibbs free energy of reaction at 1 bar and a chosen temperature, $\mathrm{J} / \mathrm{mol}$

$\Delta H_{f}^{0} \quad$ Enthalpy of formation at standard conditions, $\mathrm{J} /$ mol

$\Delta H^{0}{ }_{r} \quad$ Enthalpy of reaction at standard conditions, $\mathrm{J} / \mathrm{mol}$

$\nu_{i, j} \quad$ Stoichiometric matrix composed by $i$ components and $j$ reactions

\section{Introduction}

Several reactions are catalyzed by homogeneous and heterogeneous bases, including aldol condensation [1-4] and transesterification for product of biodiesel [5]. Aldol condensation is used for synthesis of various products ranging from basic and specialty chemicals to fragrances, flavours and pharmaceuticals [1-5]. Conventionally aldol condensation is performed using homogeneous catalysts [6, 7], such as sodium or potassium hydroxide or $\mathrm{Ti}(\mathrm{O}-\mathrm{t}-\mathrm{Bu})_{4}$ as catalysts [7]. Aldol condensation of isophorone was recently demonstrated with furanic aldehydes using $\mathrm{NaOH}$ as a catalyst for production of jet fuels [4]. Heterogeneous catalysts could facilitate a more environmentally benign way to produce chemicals, as for example in alkaline earth metal-transition metal oxide in biodiesel production [5], or in aldol condensation due to their easy separation and reuse.

Very often heterogeneous base catalysts are also quite cheap, such as aluminophosphate [1] and hydrotalcites [2], active in synthesis of 2-pentylidenecyclopentanone. In this work cross-condensation of valeraldehyde with cyclopentanone was investigated over several heterogeneous catalysts of basic nature, such as $\mathrm{Ce}-\mathrm{MgO}, \mathrm{CaO}$ and $\mathrm{Fe}$-modified $\mathrm{CaO}$ and $\mathrm{MgO}$. The aim was to study the influence of the type of base supports and methods of catalyst synthesis on the physico-chemical and catalytic properties in cross-condensation of valeraldehyde with cyclopentanone.

Besides cross-condensation per se several reactions (Fig. 1) can also occur, i.e. self-condensation of both valeraldehyde and cyclopentanone (Fig. S1) [4, 5]. In cross aldol condensation the first step is formation of hydroxylated 1-hydroxy-2-pentylcyclopentanone $\mathbf{3}$, which in the consecutive step undergoes dehydration forming an unsaturated ketone, 2-pentylidenecyclopentanone 4. This ketone being the desired product, can further react with another aldehyde forming 2,5-dipentylidenecyclopentanone 7.

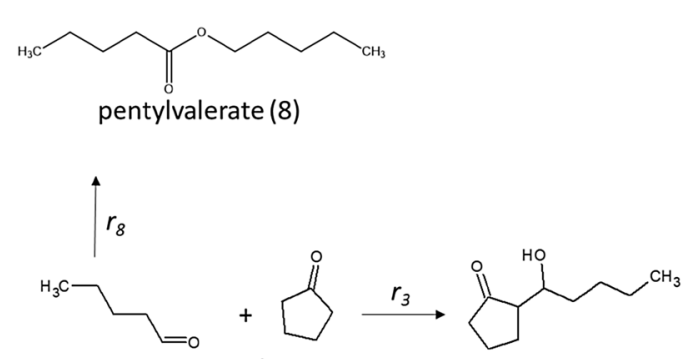

valeraldehyde cyclopentanone

1-(hydroxy)-2-pentylcyclopentanone (3)

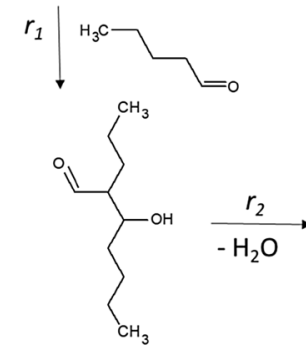

2-propyl-3-hydroxyheptanal (1)<smiles>CCCCC=C(C=O)CCC</smiles>

2-propylhept-2-enal (2)<smiles>CCCCCC1=CCCC1=O</smiles>

2-pentyl-2-cyclopenten-1-one (5)
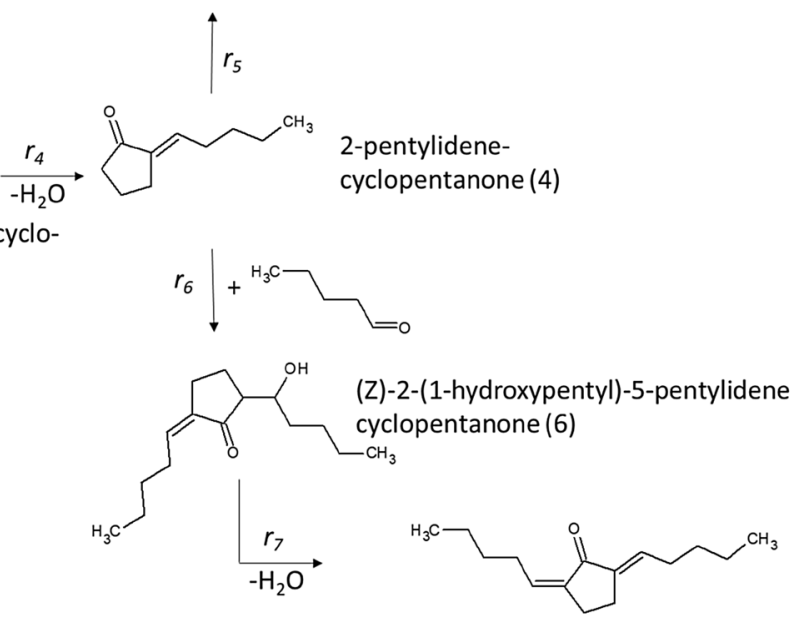

2,5-dipentylidene cyclopentanone (7)

Fig. 1 Reaction scheme for valeraldehyde condensation with cyclopentanone 
Cross-aldol condensation of valeraldehyde with cyclopentanone has been very scarcely studied over heterogeneous catalysts [1,2]. The desired product 4, 2-pentylidenecyclopentanone has been synthesized over heterogeneous hydrotalcites as catalysts giving maximally $90 \%$ yield using valeraldehyde to cyclopentanone molar ratio of $1: 5$ at $80{ }^{\circ} \mathrm{C}$ after $11 \mathrm{~h}$ via slowly adding valeraldehyde into the reactor containing cyclopentanone [2]. In another work also an excess of cyclopentanone was used in comparison with valeraldehyde in $m$-xylene as a solvent at $130{ }^{\circ} \mathrm{C}$ under nitrogen [1]. The highest selectivity of 2-pentylidenecyclopentanone, $91 \%$ at $31 \%$ conversion, was obtained at $130^{\circ} \mathrm{C}$ after $2 \mathrm{~h}$ using amorphous aluminosilicate as a catalyst.

Other reactions relevant to aldol condensation, namely self-condensation of cyclopentanone and valeraldehyde, have been also investigated. Self-condensation of cyclopentanone gives 2-cyclopentylidene-cyclopentanone, which finds applications as fuel or in hydrogenated form as fragrances and flavors $[8,9]$. This reaction occurs using potassium hydroxide as a catalyst, for example at $100{ }^{\circ} \mathrm{C}$ [8], followed by extraction with diethylether, washing and drying finally giving $73 \%$ yield. More recently also heterogeneous catalysts have been used in the synthesis of 2-cyclopentylidene-cyclopentanone by self-condensation of cyclopentanone [10]. Mesoporous $\mathrm{MgO}-\mathrm{ZrO}_{2}$ gave two main products, namely 2-cyclopentylidene-cyclopentanone composed of 10 carbon atoms and 2,5-dicyclopentylidenecyclopentanone [10]. A remarkable excess of the former product with $100 \%$ selectivity was obtained after $4.5 \mathrm{~h}$ at $8 \%$ conversion using a lower reaction temperature $110^{\circ} \mathrm{C}$. On the contrary at $130{ }^{\circ} \mathrm{C}$ selectivity was $92 \%$ at $85 \%$ conversion. The same reaction was also investigated with MOF encapsulated phosphotungstic acid as a catalyst at $130{ }^{\circ} \mathrm{C}$ under nitrogen [11]. The yield of 2-cyclopentylidene-cyclopentanone was only ca. $12 \%$ after $2 \mathrm{~h}$ because of its further transformation to trimeric compounds and after removal of hydrogen to trindane.

Self-condensation of valeraldehyde gives 2-propylhept2-enal, which has found applications as an intermediate for production of parfumes [12], and plasticizers [13, 14]. Aqueous $\mathrm{NaOH}$ is typically applied as a catalyst in industrial scale for this reaction. It was pointed out [13], that this process causes corrosion and exhibits poor product selectivity. $\mathrm{TiO}_{2}$ was confirmed to be an efficient heterogeneous catalyst for synthesis of 2-propylhept-2-enal giving very high selectivities to the desired product at $190{ }^{\circ} \mathrm{C}$ [13]. Zhao et al. [13] stated that acidity is also required for production of 2-propylhept-2-enal.

In the current work metal oxides have been applied as catalysts in aldol condensation of valeraldehyde with cyclopentanone. Since it is known that aldol condensation requires acids or bases as catalysts [15], basic supports such as $\mathrm{CaO}$ and $\mathrm{MgO}$ were modified with ceria and iron oxide, because of amphoteric nature of ceria and Lewis acidity of iron oxide. Therefore, not surprisingly, iron oxides have been used as catalysts in cyclohexanone aldol condensation [16], while cesium was utilized in aldol condensation of heptanal with benzaldehyde [17]. The aim in this work was to reveal the role of basic and acid active sites, metal functions in aldol condensation of valeraldehyde with cyclopentanone and investigate reaction kinetics and thermodynamics. The acidity and basicity of the catalysts were quantified by $\mathrm{NH}_{3}$ and $\mathrm{CO}_{2}$ temperature programmed desorption techniques. According to our knowledge this is the first time when kinetics and thermodynamics of valeraldehyde-cyclopentanone aldol condensation are reported.

\section{Experimental Section}

\subsection{Catalyst Synthesis}

Fe-modified $\mathrm{MgO}$ and $\mathrm{CaO}$ and $\mathrm{Ce}$-modified $\mathrm{MgO}$ catalysts were prepared using deposition precipitation (DP) and evaporation impregnation (EIM) methods. The $\mathrm{CeO}_{2}-\mathrm{MgO}-\mathrm{DP}$ catalyst was prepared via dissolving cerium nitrate in distilled water adding thereafter $\mathrm{MgO}$ into the cerium nitrate aqueous solution. In the deposition-precipitation procedure, $\mathrm{pH}$ was first increased to 10 with ammonium hydroxide solution (25\%) to precipitate cerium followed by stirring the slurry at $150 \mathrm{rpm}$ for $24 \mathrm{~h}$. After that, the catalyst was filtered and washed with distilled water. $\mathrm{CeO}_{2}-\mathrm{MgO}-\mathrm{DP}$ catalyst was dried in an oven at $100{ }^{\circ} \mathrm{C}$ for $7 \mathrm{~h}$. Decomposition of cerium nitrate was carried out by thermal treatment of $\mathrm{CeO}_{2}-\mathrm{MgO}-\mathrm{DP}$ catalyst in a muffle oven using a step calcination procedure. The catalyst designated as $\mathrm{CeO}_{2}-\mathrm{MgO}-\mathrm{DP}$.

$\mathrm{FeO}-\mathrm{MgO}-\mathrm{DP}$ catalyst was prepared using aqueous solution of ferric nitrate by a deposition precipitation method. The $\mathrm{pH}$ was increased to 10 using ammonium hydroxide solution (25\%) and the synthesis carried out for $24 \mathrm{~h}$, which was followed by drying at $100{ }^{\circ} \mathrm{C}$ for $7 \mathrm{~h}$ and calcination in a muffle oven. The catalyst designated as $\mathrm{Fe}-\mathrm{MgO}-\mathrm{DP}$.

The aqueous solution of the ferric nitrate precursor was mixed with $\mathrm{CaO}$ and kept in a rotary evaporator for $24 \mathrm{~h}$ at the stirring speed of $50 \mathrm{rpm}$. In the subsequent step, the water phase was evaporated. The catalyst was removed from the rotatory flask and dried in an oven at $100{ }^{\circ} \mathrm{C}$ for $7 \mathrm{~h}$. Decomposition of cerium nitrate was carried out in a muffle oven at $450{ }^{\circ} \mathrm{C}$ for $4 \mathrm{~h}$ using a step calcination procedure. The catalyst was designated as $\mathrm{Fe}-\mathrm{CaO}-\mathrm{EIM}$.

\subsection{Catalyst Characterization Methods}

The Philips X'Pert Pro MPD X-ray powder diffractometer was used in the XRD measurements. The diffractometer 
was operated in Bragg-Brentano diffraction mode, and the monochromatized $\mathrm{Cu}-\mathrm{K} \alpha$ radiation $(\lambda=1.541874 \AA)$ was generated with a voltage of $40 \mathrm{kV}$ and a current of $45 \mathrm{~mA}$. The measured diffractograms were analyzed with Philips X'Pert HighScore and MAUD [18] programs. The Powder Diffraction File 2 (PDF-2) database, Inorganic Crystal Structure Database (ICSD), and Crystallography Open Database (COD) were used as references [19-21]

The scanning electron microscopy coupled with an energy dispersive $\mathrm{X}$-ray analyzer was utilized to study morphology of the fresh catalysts using Zeiss Leo Gemini 1530 microscope combined with secondary electron and backscattered electron detectors. Acceleration voltage of $15 \mathrm{kV}$ was used for X-ray analyzer. In order to perform analysis, the catalyst was placed as a thin layer on top of the carbon coating to enhance the conductivity and allow high quality of magnified images.

The transmission electron microscopy was utilized to study the structural properties, porosity, metal particle size and distribution using JEM-1400Plus (by JEOL ltd. Japan) of $120 \mathrm{kV}$ maximal acceleration voltage. Interpretation of TEM images and determination of the particles sizes of the fresh and spent catalyst were done using ImageJ program.

The specific surface area was determined with Sorptometer 1900 (Carlo Erba Instrument) using nitrogen physisorption. The catalysts were outgassed at $150{ }^{\circ} \mathrm{C}$ for $3 \mathrm{~h}$ prior to the measurement. The BET equation was used to calculate the specific surface area.

$\mathrm{CO}_{2}$ TPD measurements were performed to determine the concentration of basic sites using Autochem 2010, Micromeritics instrument. The catalyst, $200 \mathrm{mg}$, was first dried at $150{ }^{\circ} \mathrm{C}$ for $30 \mathrm{~min}$ under helium (AGA, 99.996\%) after which it was cooled to $100{ }^{\circ} \mathrm{C}$. Thereafter $\mathrm{CO}_{2}$ (AGA) was adsorbed on the catalyst surface during $30 \mathrm{~min}$. The physisorbed $\mathrm{CO}_{2}$ was flushed from the catalyst surface at $100^{\circ} \mathrm{C}$ for $30 \mathrm{~min}$ after which the temperature was increased by $10{ }^{\circ} \mathrm{C} / \mathrm{min}$ up to $700{ }^{\circ} \mathrm{C}$.

Ammonia TPD was performed with Micromeritics (AutoChem 2910) using helium as a carrier gas. The sample was dried prior to the measurement at $250{ }^{\circ} \mathrm{C}$ for $30 \mathrm{~min}$ after which ammonia ( $5 \mathrm{vol} \%$ in helium, AGA) was adsorbed on the catalyst for $60 \mathrm{~min}$ at $25{ }^{\circ} \mathrm{C}$. Then the gas supply was stopped and these conditions were hold for $30 \mathrm{~min}$. In the next step the temperature was increased by $10^{\circ} \mathrm{C} / \mathrm{min}$ to $100{ }^{\circ} \mathrm{C}$ and hold at $100^{\circ} \mathrm{C}$ for $30 \mathrm{~min}$. The ammonia TPD was measured using the following temperature programme: $100{ }^{\circ} \mathrm{C}-10{ }^{\circ} \mathrm{C} / \mathrm{min}-600{ }^{\circ} \mathrm{C}$.

\subsection{Kinetic Experiments}

Catalytic experiments were typically performed under flowing helium at $130{ }^{\circ} \mathrm{C}$ in a glass reactor equipped with a stirrer. Typically valeraldehyde (Aldrich, 97\%) was reacting with an excess of cyclopentanone (Sigma Aldrich, > 99\%), which was also applied as a solvent $(60 \mathrm{ml})$, if not otherwise stated. The initial valeraldehyde concentration was $0.50 \mathrm{~mol} / \mathrm{l}$ if not specifically mentioned. The experiments were performed by adding valeraldehyde, cyclopentanone and the catalyst into the cold reactor, which was then heated to $130{ }^{\circ} \mathrm{C}$. The reactor system was equipped with a condenser, which exhibited temperature close to zero. Valeraldehyde and a part of cyclohexanone were thus condensed back to the liquid phase. The experiments were carried out under argon atmosphere. The weight ratio of valeraldehyde to cyclopentanone in the kinetic experiments was 0.05 , while the amount of catalyst was $1.6 \mathrm{~g}$. The mass ratio of valeraldehyde to catalyst was 1.7 being the same as was used in [1]. Small catalyst particles (below $63 \mu \mathrm{m}$ ) were used under vigorous stirring $(600 \mathrm{rpm})$ to avoid internal and external mass transfer limitations. In some experiments mesitylene (Sigma Aldrich, 97\%) was used as a solvent. The products were analyzed by a GC equipped with HP- 5 column (30 m, $\mathrm{d}_{\mathrm{i}}=320 \mu \mathrm{m}$, film thickness $0.5 \mu \mathrm{m}$ ) using the following temperature programme: $60{ }^{\circ} \mathrm{C}(2 \mathrm{~min})-8{ }^{\circ} \mathrm{C} / \mathrm{min}-124^{\circ} \mathrm{C}-4{ }^{\circ} \mathrm{C} /$ min-200 ${ }^{\circ} \mathrm{C}-12{ }^{\circ} \mathrm{C} / \mathrm{min}-280{ }^{\circ} \mathrm{C}(10 \mathrm{~min})$. The reaction products were identified by GC-MS (Agilent Technologies, $6870 \mathrm{~N})$ equipped with DB-1 column $(30 \mathrm{~m}, 250 \mu \mathrm{m}$, film thickness $0.50 \mu \mathrm{m})$.

\section{Results and Discussion}

\subsection{Catalyst Characterization Results}

XRD results revealed that $\mathrm{FeO}-\mathrm{CaO}-\mathrm{EIM}$ catalyst contained iron only as $\mathrm{Ca}_{2} \mathrm{Fe}_{2} \mathrm{O}_{5}$ phase (Table 1; Fig. 2). $\mathrm{Ca}_{2} \mathrm{Fe}_{2} \mathrm{O}_{5}$ in [22] was prepared by coprecipitation of $\mathrm{Ca}$ and $\mathrm{Fe}$ nitrates and calcined at $500{ }^{\circ} \mathrm{C}$. The size of $\mathrm{Ca}_{2} \mathrm{Fe}_{2} \mathrm{O}_{5}$ is about $60 \mathrm{~nm}$ based on XRD [23]. On the other hand, metal oxide $\mathrm{Fe}_{2} \mathrm{O}_{3}$ particles are threefold smaller than $\mathrm{Ca}_{2} \mathrm{Fe}_{2} \mathrm{O}_{5}$ (Table 1). $\mathrm{XRD}$ results of $\mathrm{CeO}_{2}-\mathrm{MgO}$ showed the presence of cubic $\mathrm{CeO}_{2}$ [24] and $\mathrm{MgO}$ [28] (Table 2). XRD of FeO-MgO$\mathrm{DP}$ displayed only the presence of cubic $\mathrm{MgO}$. This result indicates that iron either is in an amorphous form or it well dispersed on the support with the particle size below $3 \mathrm{~nm}$, not being detectable by XRD.

SEM images of different catalysts are depicted in Fig. 3. $\mathrm{CeO}_{2}-\mathrm{DP}$ exhibits both spherical and plate-like character (Fig. 3a). FeO-MgO-DP contains plates (Fig. 3b) whereas $\mathrm{FeO}-\mathrm{CaO}-\mathrm{EIM}$ exhibited large spherical particles between 105 and 148 nm (Fig. 3c). Particles in FeO-CaO-EIM were both of irregular and spherical shapes in the range of 50 to $600 \mathrm{~nm}$ (Fig. 3d). The particle sizes in $\mathrm{CaO}$ varied in a broader range of 50 to $400 \mathrm{~nm}$. These changes can be related to the presence of different phases in these materials. $\mathrm{CaO}$ is 
Table 1 Phase composition and particle size of $\mathrm{CaO}$ and $\mathrm{FeO}-$ CaO-EIM determined by XRD $[24,25]$

\begin{tabular}{|c|c|c|c|c|c|c|}
\hline \multirow[t]{2}{*}{ Phase } & \multirow[t]{2}{*}{ Framework } & \multirow[t]{2}{*}{ hkl at $2 \Theta\left({ }^{\circ}\right)$} & \multicolumn{2}{|l|}{$\mathrm{CaO}$} & \multicolumn{2}{|c|}{ FeO-CaO-EIM } \\
\hline & & & $\mathrm{wt} \%$ & $\mathrm{D}(\mathrm{nm})$ & $\mathrm{wt} \%$ & $\mathrm{D}(\mathrm{nm})$ \\
\hline $\mathrm{CaCO}_{3}$ & Rhombohedral & 104 (29.40), $018(47.38)$ & $16 \pm 6$ & $38 \pm 25$ & $19 \pm 17$ & $92 \pm 55$ \\
\hline $\mathrm{Ca}(\mathrm{OH})_{2}$ & Hexagonal & $\begin{array}{r}001(17.98), 104(29.40), \\
101(34,12), 102(47.38)\end{array}$ & $83 \pm 5$ & $26 \pm 6$ & $52 \pm 6$ & $24 \pm 7$ \\
\hline $\mathrm{Fe}_{2} \mathrm{O}_{3}$ & Rhombohedral & 104 (33.18), $024(49.52)$ & 0 & 0 & 0 & 0 \\
\hline $\mathrm{Ca}_{2} \mathrm{Fe}_{2} \mathrm{O}_{5}$ & Orthorhombic & $\begin{array}{r}020(11.99), 002,(32.00) \\
200(33.06), 141(33.49)\end{array}$ & 0 & 0 & $22 \pm 8$ & $60 \pm 12$ \\
\hline $\mathrm{CaO}$ & Cubic & $200(37.38), 220(53.90)$ & $1 \pm 1$ & n.d & $7 \pm 3$ & $65 \pm 30$ \\
\hline
\end{tabular}

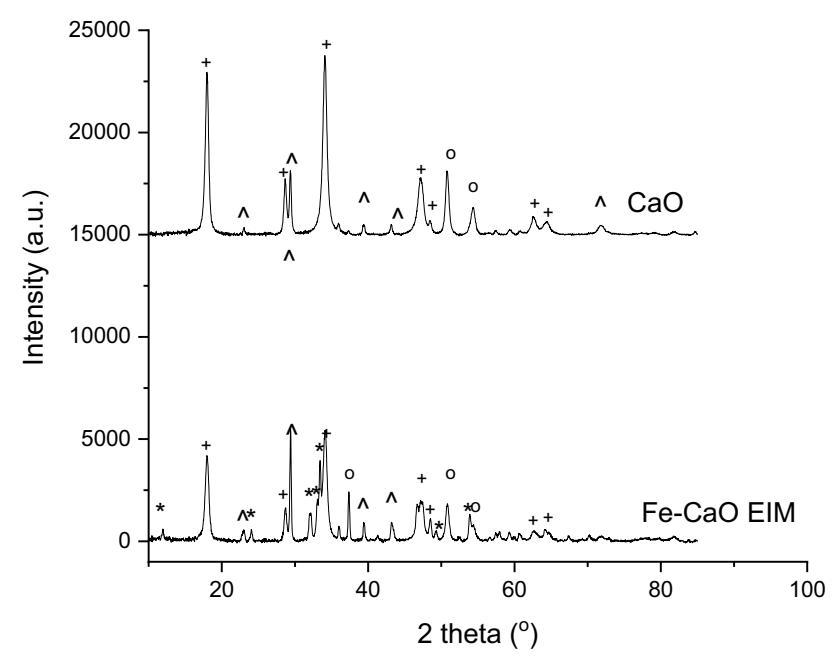

Fig. 2 XRD patterns from $\mathrm{CaO}$, and $\mathrm{FeO}-\mathrm{CaO}-\mathrm{EIM}$. Notation: $\mathrm{Ca}(\mathrm{OH})_{2}+, \mathrm{CaCO}_{3}{ }^{\wedge}, \mathrm{CaO}$ o, $\mathrm{Ca}_{2} \mathrm{Fe}_{2} \mathrm{O}_{5}{ }^{*}, \mathrm{Fe}_{2} \mathrm{O}_{3} \#$

Table 2 Phase composition and particle size of $\mathrm{FeO}-\mathrm{MgO}-\mathrm{DP}$ and $\mathrm{CeO}-\mathrm{MgO}$ catalysts determined by XRD [24, 26-28]

\begin{tabular}{llllc}
\hline Catalyst & Phase & Framework & wt\% & $\mathrm{D}(\mathrm{nm})$ \\
\hline $\mathrm{FeO}-\mathrm{MgO}-\mathrm{DP}$ & $\mathrm{MgO}$ & Cubic & 100 & $20 \pm 2.0$ \\
$\mathrm{CeO}_{2}-\mathrm{MgO}-\mathrm{DP}$ & $\mathrm{CeO}_{2}$ & Cubic & $31 \pm 19$ & $9.0 \pm 2.0$ \\
& $\mathrm{MgO}$ & Cubic & $69 \pm 19$ & $17 \pm 3$ \\
\hline
\end{tabular}

rich in hexagonal $\mathrm{Ca}(\mathrm{OH})_{2}$, however, $\mathrm{FeO}-\mathrm{CaO}-\mathrm{EIM}$ contained mainly $\mathrm{CaCO}_{3}$.

The TEM images showed also large differences in the particle sizes and shapes (Fig. 4). FeO-CaO-EIM contains spherical particles (Fig. 4a), whereas the parent $\mathrm{CaO}$ exhibited 10 to $50 \mathrm{~nm}$ particles which were not easy to separate from each other.

Basicity determined by $\mathrm{CO}_{2}$ temperature programmed desorption showed that pure $\mathrm{CaO}$ exhibited the highest basicity in accordance with the literature (Table 3; Fig. 5a) $[23,29]$. CaO contained large amounts of medium and strong acid sites. When $\mathrm{CaO}$ was modified by $\mathrm{Fe}$ using the evaporation impregnation method its basicity decreased to
$59 \%$ of the initial value for pristine $\mathrm{CaO}$ due to a relatively high Fe loading, $10 \%$. In addition the concentration of strong basic sites decreased in this catalyst by iron modification being only $21 \%$ of that of $\mathrm{CaO}$. Nevertheless, basicity of $\mathrm{FeO}-\mathrm{CaO}-\mathrm{EIM}$ was quite high, partially due to high basicity of $\mathrm{Ca}_{2} \mathrm{Fe}_{2} \mathrm{O}_{5}$ (Fig. 5a) [5], which was comparative to the parent $\mathrm{CaO}$. The composite material $\mathrm{CeO}_{2}-\mathrm{MgO}-\mathrm{DP}$ with $24 \mathrm{wt} \%$ Ce exhibited a total basicity higher than the pristine $\mathrm{MgO}$. The amount of strong basic sites in both $\mathrm{CeO}_{2}-\mathrm{MgO}-\mathrm{DP}$ was, however, quite low compared to the parent $\mathrm{MgO}$, which according to the literature exhibits more strong basic sites than $\mathrm{CeO}_{2}$ [30].

Acidity, determined by ammonia TPD, follows the order (Table 3; Fig. 5 b): 21 wt $\% \mathrm{CeO}_{2}-\mathrm{MgO}-\mathrm{DP}>10 \mathrm{wt} \%$ $\mathrm{FeO}-\mathrm{CaO}-\mathrm{EIM}>7 \mathrm{wt} \% \mathrm{FeO}-\mathrm{MgO}-\mathrm{DP}$. The lowest acidity was measured for $\mathrm{FeO}-\mathrm{MgO}-\mathrm{DP}$, containing the lowest metal amount. In fact for this material no $\mathrm{Fe}_{2} \mathrm{O}_{3}$ was observed according to XRD (Table 2) and most probable iron is present in the form of finely dispersed iron oxide particles. Results in Table 3 showing some acidity for $\mathrm{FeO}-\mathrm{MgO}-\mathrm{DP}$ can be interpreted by taking into account that $\mathrm{Fe}_{2} \mathrm{O}_{3}$ exhibits both Brønsted and Lewis acidity [31]. The highest acidity of $\mathrm{CeO}_{2}-\mathrm{MgO}-\mathrm{DP}$ is explained by its high $\mathrm{CeO}_{2}$ loading. It is known that $\mathrm{CeO}_{2}$ is amphoteric which influences its acidic and basic properties. Acidity of $10 \mathrm{wt} \%$ $\mathrm{FeO}-\mathrm{CaO}-\mathrm{EIM}$ is related to presence of iron +3 possessing Lewis acidity [32] in the form of $\mathrm{Ca}_{2} \mathrm{Fe}_{2} \mathrm{O}_{5}$.

\subsection{Reaction Network and Thermodynamic Analysis}

The reaction network for aldol condensation of valeraldehyde with cyclopentanone is shown in Fig. 1. It should be pointed out here, that as mentioned in the Introduction self-condensation of cyclopentanone forming 2-cyclopentylidene-cyclopentanone, requires presence of strong basicity, thus its contribution to valeraldehyde self- and cross-condensation reactions was considered to be less significant. According to the literature [2] valeraldehyde condensation proceeds via formation of an intermediate 1-hydroxy2-pentylcyclopentanone $\mathbf{3}$, which is dehydrated forming the desired product 2-pentylidenecyclopentanone 4 . In addition 

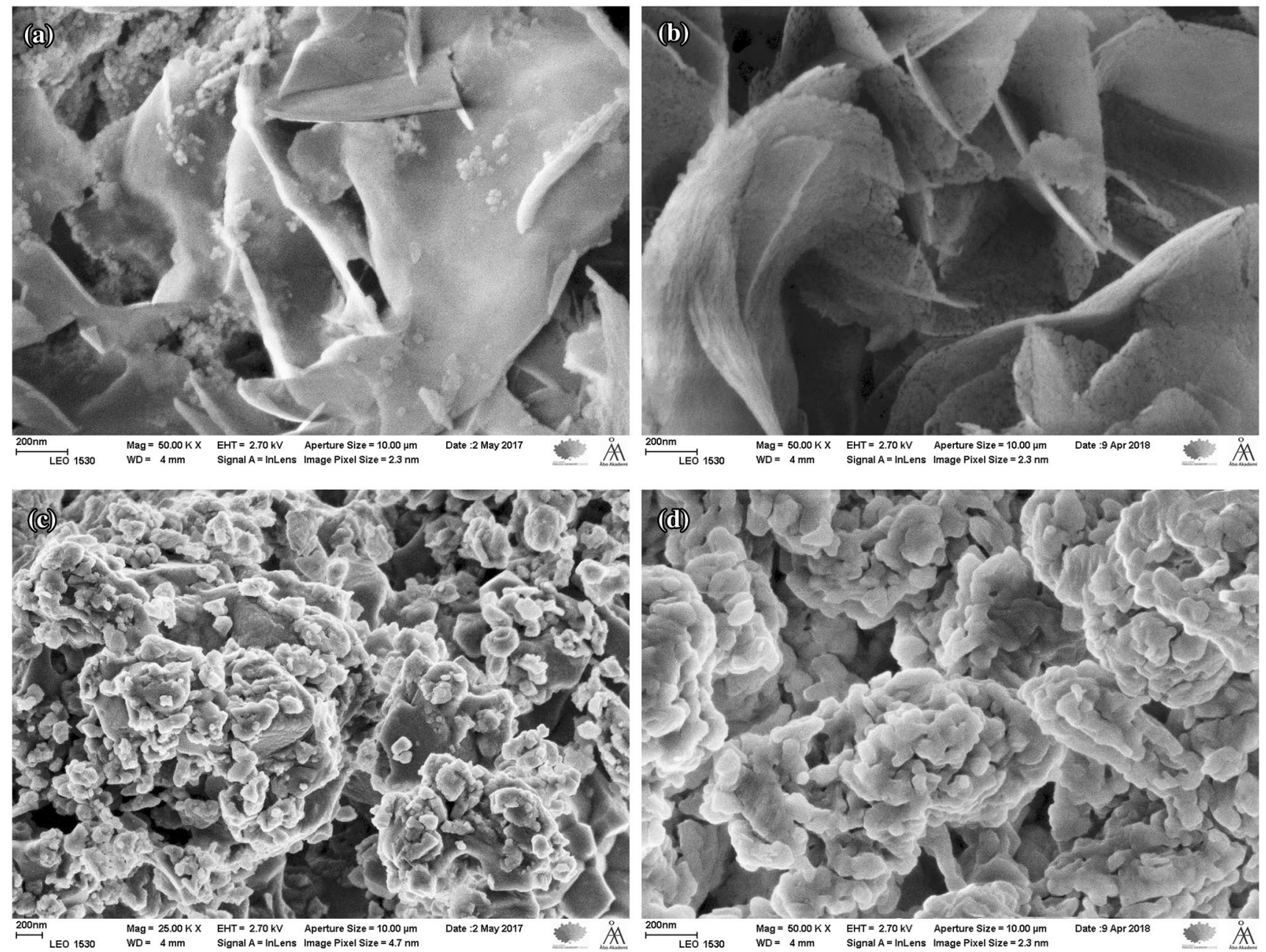

Fig. 3 SEM images of a $\mathrm{CeO}_{2}-\mathrm{MgO}-\mathrm{DP}$, b FeO-MgO-DP, $\mathbf{c}$ FeO-CaO-EIM, and d $\mathrm{CaO}$

Fig. 4 TEM images of a $\mathrm{FeO}-$ $\mathrm{CaO}-\mathrm{EIM}, \mathbf{b} \mathrm{CaO}$

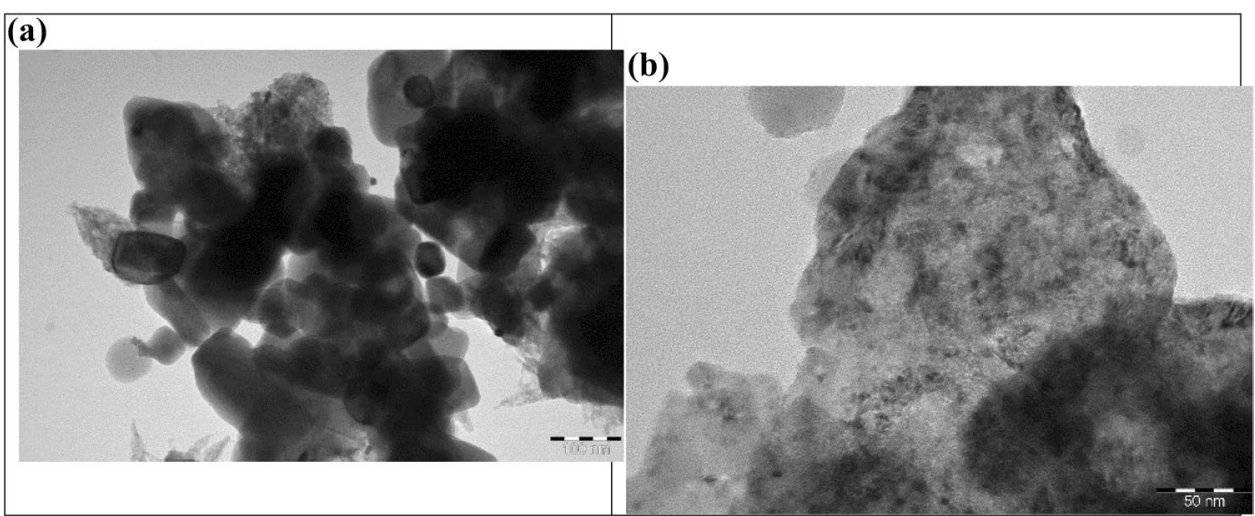

to formation of the desired cross-condensation product, the latter can also be isomerized to 2-pentyl-2-cyclopenten1-one 5, especially at higher temperature, when this isomer is thermodynamically more stable than the desired product 4 [2]. The desired product can also react further with another valeraldehyde molecule giving 2-(1-hydropentyl)-5-pentylidene cyclopentanone $\mathbf{6}$ and its corresponding dehydrated product, 2,5-dipentylidene cyclopentanone 7. Furthermore, other reactions can also occur, namely self-condensation of valeraldehyde giving 2-propyl-3-hydroxyheptanal, 1 which 
Table 3 Metal content, basicity and acidity of the catalysts

\begin{tabular}{|c|c|c|c|c|c|c|c|}
\hline \multirow[t]{2}{*}{ Catalyst } & \multirow{2}{*}{$\begin{array}{l}\text { Metal content } \\
\text { by EDXA } \\
(\mathrm{wt} \%)\end{array}$} & \multicolumn{4}{|c|}{ Amount of basic sites } & \multirow{2}{*}{$\begin{array}{l}\text { Amount of } \mathrm{NH}_{3} \\
\text { desorbed }(\mu \mathrm{mol} / \\
\left.\mathrm{g}_{\text {cat }}\right)\end{array}$} & \multirow{2}{*}{$\begin{array}{l}\mathrm{T}_{\max }\left({ }^{\circ} \mathrm{C}\right) \\
\text { for ammonia } \\
\text { desorption }\end{array}$} \\
\hline & & $\begin{array}{l}\text { Weak (desorbed } \\
\left.\text { below } 277^{\circ} \mathrm{C}\right) \\
\mu \mathrm{mol} / \mathrm{g}_{\text {cat }}\end{array}$ & $\begin{array}{l}\text { Medium (desorbed } \\
\text { between } 277- \\
\left.477^{\circ} \mathrm{C}\right) \mu \mathrm{mol} / \mathrm{g}_{\text {cat }}\end{array}$ & $\begin{array}{l}\text { Strong (desorbed } \\
\left.\text { above } 477^{\circ} \mathrm{C}\right) \\
\mu \mathrm{mol} / \mathrm{g}_{\text {cat }}\end{array}$ & $\begin{array}{l}\text { Sum of } \\
\text { basic } \\
\text { sites }\end{array}$ & & \\
\hline $\mathrm{CaO}$ & 0 & 22 & 905 & 1179 & 2105 & n.d & n.d \\
\hline $\mathrm{FeO}-\mathrm{CaO}-\mathrm{EIM}$ & 10 & 13 & 962 & 259 & 1234 & 305 & 430 \\
\hline $\mathrm{MgO}$ & 0 & 99 & 731 & 168 & 989 & n.d & n.d \\
\hline FeO-MgO-DP & 7.0 & 222 & 354 & 118 & 695 & 45 & 306 \\
\hline $\mathrm{CeO}_{2}-\mathrm{MgO} \mathrm{DP}$ & 24 & 76 & 967 & 43 & 1087 & 152 & 380 \\
\hline
\end{tabular}
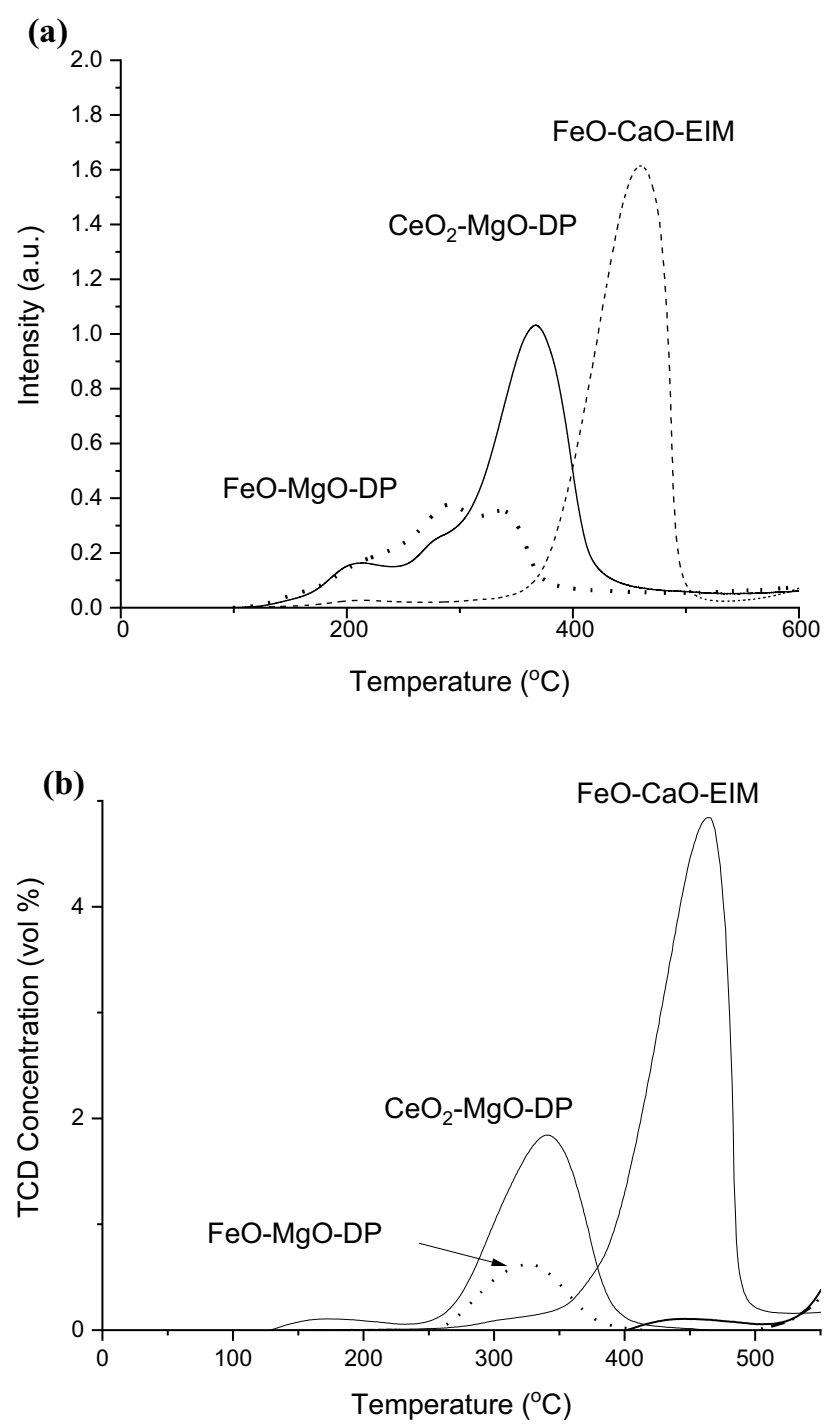

Fig. 5 a $\mathrm{CO}_{2}$ TPD of FeO-CaO-EIM, FeO-MgO-DP and $\mathrm{CeO}_{2}-$ $\mathrm{MgO}-\mathrm{DP}, \mathbf{b} \mathrm{NH}_{3}$ TPD of FeO-CaO-EIM and $\mathrm{CeO}_{2}-\mathrm{MgO}-\mathrm{DP}$

can be dehydrated to the corresponding unsaturated aldehyde, 2-propylhept-2-enal 2 . In the current case no pentyl valerate $\mathbf{8}$ could be seen, which in general can be formed via the Tischenko reaction.

Aldol condensation can occur both on basic and acid sites according to the literature suggestions [2]. Cross aldol condensation over basic sites can be described by a mechanism, [2] when the base accepts a proton from the ketone forming in the current case negatively charged $\mathrm{O}^{-}$in cyclopentenone which attacks the aldehyde via a nucleophile forming hydroxypentylcyclopentanone. Dehydration occurs via formation of a carbocation which after deprotonation gives 2-pentylidenecyclopentanone.

In acid catalyzed aldol condensation the reaction has been proposed to start with enolization of the aldehyde over Lewis acid sites. Subsequently the carbocation formed from the aldehyde on Brønsted acid site reacts with the enol leading to formation of a cross condensation product [33].

While the main focus in this work was on kinetics of the cross condensation of valeraldehyde with cyclopentanone, in order to understand if thermodynamics governs the overall reaction, first thermodynamic analysis was performed. According to our knowledge thermodynamics for the cross condensation and relevant reactions has not been reported. Evaluation of thermodynamics was done by calculating enthalpy $\left(\Delta H_{r}^{0}\right)$ and Gibbs free energy $\left(\Delta G_{r}^{0}\right)$ at standard conditions using the approach from [34] and starting from the standard enthalpy $\left(\Delta H_{f}^{0}\right)$ and Gibbs free energy $\left(\Delta G_{f}^{0}\right.$ ) of formation from the elements estimated with the Joback approach [35-37]:

$\Delta H_{r, j}^{0}=\sum_{j} v_{i, j} \cdot \Delta H_{f, i}^{0}$

$\Delta G_{r, j}^{0}=\sum_{j} v_{i, j} \cdot \Delta G_{f, i}^{0}$

The equilibrium constant of each reaction was calculated from its definition

$K_{j}^{0}=\exp \left(-\frac{\Delta G_{r, i}^{0}}{R T}\right)$ 
Table 4 Enthalpy and Gibbs free energy formation for each component ( $i$ ) (given in bold) and stoichiometric matrix for component $i$ for reaction $j$

\begin{tabular}{|c|c|c|c|c|c|c|c|c|c|c|c|}
\hline Component & $\Delta \mathrm{H}_{\mathrm{f}}^{0}(\mathrm{~kJ} / \mathrm{mol})$ & $\Delta \mathrm{G}_{\mathrm{f}}^{0}(\mathrm{~kJ} / \mathrm{mol})$ & $\mathrm{i} / \mathrm{j}$ & 1 & 2 & 3 & 4 & 5 & 6 & 7 & 8 \\
\hline Valeraldehyde & -232 & -108 & 1 & -2 & 0 & -1 & 0 & 0 & -1 & 0 & -2 \\
\hline 2-Propyl-3-hydroxyheptanal & -498 & -20.8 & 2 & 1 & -1 & 0 & 0 & 0 & 0 & 0 & 0 \\
\hline 2-Propylhept-2-enal & -228 & 5.47 & 3 & 0 & 1 & 0 & 0 & 0 & 0 & 0 & 0 \\
\hline Cyclopentanone & -195 & -87.1 & 4 & 0 & 0 & -1 & 0 & 0 & 0 & 0 & 0 \\
\hline 1-Hydroxy-2-pentylcyclopentanone & -484 & -192 & 5 & 0 & 0 & 1 & -1 & 0 & 0 & 0 & 0 \\
\hline Water & -242 & -228 & 6 & 0 & 1 & 0 & 1 & 0 & 0 & 1 & 0 \\
\hline 2-Pentylidenecyclopentanone & -231 & 0.45 & 7 & 0 & 0 & 0 & 1 & -1 & -1 & 0 & 0 \\
\hline 2-Pentyl-2-cyclopenten-1-one & -260 & -24.7 & 8 & 0 & 0 & 0 & 0 & 1 & 0 & 0 & 0 \\
\hline $\begin{array}{l}\text { (Z)-2-(1-hydroxypentyl)-5-2-pentyl- } \\
\text { idenecyclopentanone }\end{array}$ & -512 & -104 & 9 & 0 & 0 & 0 & 0 & 0 & 1 & -1 & 0 \\
\hline 2,5-Dipentylidene cyclopentanone & -258 & 88.0 & 10 & 0 & 0 & 0 & 0 & 0 & 0 & 1 & 0 \\
\hline Pentyl-valerate & -495 & -201 & 11 & 0 & 0 & 0 & 0 & 0 & 0 & 0 & 1 \\
\hline
\end{tabular}

Table 5 Enthalpy and Gibbs free energy for each reaction $(j)$ at standard conditions, equilibrium constants at standard conditions $\left(K_{j}^{0}\right)$

\begin{tabular}{lccl}
\hline$j$ & $\Delta H_{r, j}^{0}(\mathrm{~kJ} / \mathrm{mol})$ & $\Delta G_{r, j}^{0}(\mathrm{~kJ} / \mathrm{mol})$ & $K_{j}^{0}$ \\
\hline 1 & -33.9 & 0.87 & $2.99 \times 10^{-2}$ \\
2 & 28.4 & -15.1 & $4.37 \times 10^{2}$ \\
3 & -57.6 & 0.34 & $2.51 \times 10^{-1}$ \\
4 & 12.1 & -36.0 & $2.04 \times 10^{6}$ \\
5 & -29.7 & -25.1 & $2.53 \times 10^{4}$ \\
6 & -48.9 & 0.34 & $2.51 \times 10^{-1}$ \\
7 & 12.1 & -36.0 & $2.04 \times 10^{6}$ \\
8 & -30.3 & 16.0 & $1.57 \times 10^{-3}$ \\
\hline
\end{tabular}

The dependence of the reaction free Gibbs energy on temperature was included by implementing the Gibbs-Helmholtz equation valid at $P=1 \operatorname{bar}\left(\Delta G_{r, j}^{\Phi}\right)$

$\frac{\Delta G_{r, j}^{\varphi}(T)}{T}=\frac{\Delta G_{r, j}^{0}}{T^{0}}+\Delta H_{r, j}^{0}\left(\frac{1}{T}-\frac{1}{T^{0}}\right)$

The calculated enthalpy and Gibbs free energy formation for each component $(i)$ are reported in Table 4. Numbering of reactions is from Fig. 1.

Starting from these values, the enthalpy and Gibbs free energy for each reaction $(j)$ at standard conditions, equilibrium constants at standard conditions $\left(K_{j}^{0}\right)$, enthalpy and Gibbs free energy at different temperatures and pressure were calculated. A temperature range between $T_{\text {min }}=353.15 \mathrm{~K}$ and $T_{\text {max }}=423.15 \mathrm{~K}$ was investigated. It can be seen that thermodynamically most favorable reactions are 4 and 7 , namely dehydration of the intermediate

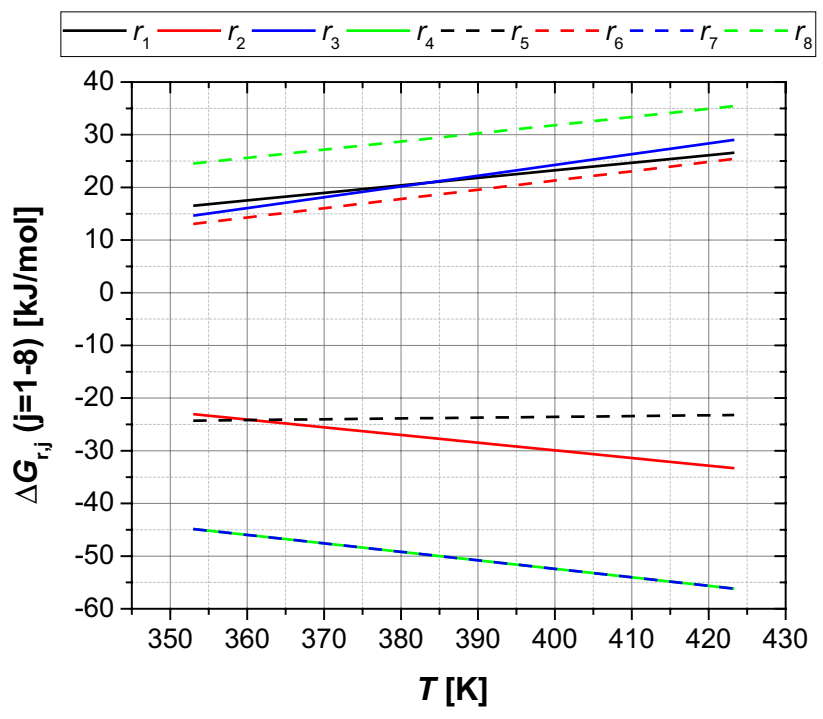

Fig. 6 Gibbs free energy for each reaction $(j)$ as a function of temperature

2-hydroxyl-2-pentylcyclopentanone to the desired product and formation of 2,5-dipentylidene cyclopentanone (Table 5; Fig. 6). It can also be seen from Fig. 6 that both of these reactions become even more thermodynamically feasible at higher temperatures. Interestingly the $\Delta \mathrm{G}$ for formation of 2-pentyl-2-cyclopentyl-1-one, isomer of the desired product, was independent on temperature.

\subsection{Catalytic Results}

In the preliminary work valeraldehyde condensation with cyclopentanone was investigated using mesitylene as a solvent, since in [1] successful aldol condensation in this reaction was reported to occur in another substituted aromatic compound, $o$-xylene, as a solvent. In the current work 
aldol condensation of valeraldehyde with cyclopentanone was performed analogously to the work of Hasni et al. [1] using 1:5 molar ratio of the reactants, however, instead of $m$-xylene in mesitylene as a solvent over $\mathrm{CeO}_{2}-\mathrm{MgO}-\mathrm{DP}$. The results showed, however, that with a low initial valeraldehyde concentration $(0.09 \mathrm{~mol} / \mathrm{l})$ in mesitylene as a solvent, mainly self-condensation products of valeraldehyde (98\%) were formed in $3 \mathrm{~h}$ at $56 \%$ conversion at $130{ }^{\circ} \mathrm{C}$, when $1: 5$ molar ratio of valeraldehyde to cyclopentanone was applied. In addition, minor oxidation of mesitylene occurred resulting in formation of 3,5-dimethylbenzaldehyde, confirmed by GC-MS, which might be possible by lattice oxygen originating from $\mathrm{CeO}_{2}$. After the initial experiments in mesitylene as a solvent, valeraldehyde condensation was subsequently performed using cyclopentanone both as a solvent and a reactant.

Both the thermal reaction between valeraldehyde and cyclohexanone in the absence of any catalyst as well as catalytic experiments were carried out using an excess of cyclopentanone. The concentration profiles for valeraldehyde and its self- and cross-condensation products are shown in Figs. 7, 8, 9, 10, 11, 12. In thermal cross condensation of valeraldehyde at the initial concentration of $0.53 \mathrm{~mol} / 1 \mathrm{9} \%$ conversion of valeraldehyde was obtained. The main product was 2-propylhept-2-enal. In addition relative large amounts of both 2-propyl-3-hydroxyheptanal, identified based on the confirmation of the $\mathrm{m} / \mathrm{z}+$ peak at 173 in GC-MS analysis reported in [38] and 1-hydroxy-2-pentylcyclopentanone and

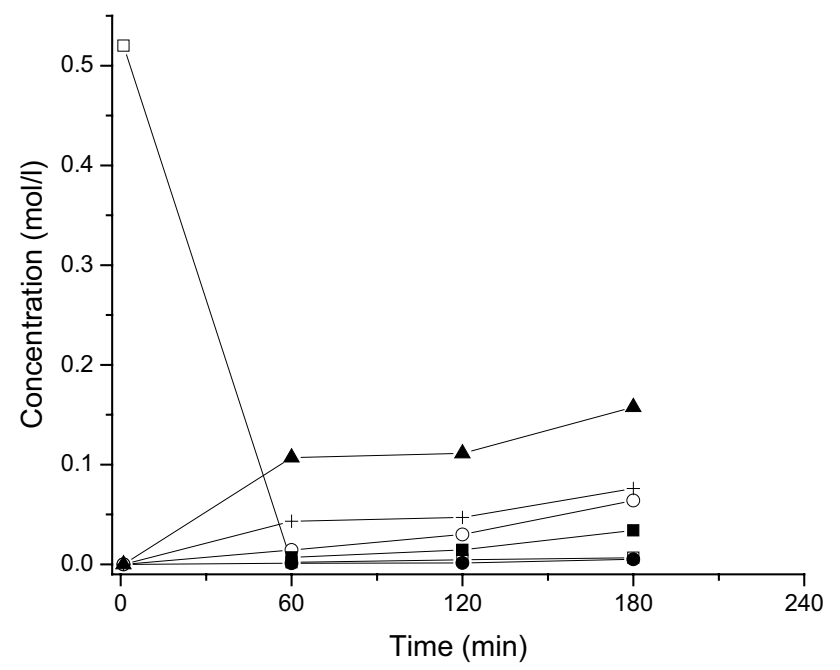

Fig. 7 Concentration of valeraldehyde and its self- and cross-condensation products as a function of time in valeraldehyde cross-condensation with cyclopentanone. The initial valeraldehyde concentration was $0.53 \mathrm{~mol} / \mathrm{l}$ in cyclohexane. The experiments were performed at $130{ }^{\circ} \mathrm{C}$ under argon flow. Symbols: valeraldehyde (white square), 2-pentylidenecyclopentanone 4 (black circle), 2-pentyl-2-cyclopent1-one 5 (white circle), 2-propyl-3-hydroxyheptanal (+) 1, 2-propylhept-2-enal (black up-pointing triangle) 2 and 1-hydroxy-2-pentylcyclopentanone (black square) $\mathbf{3}$

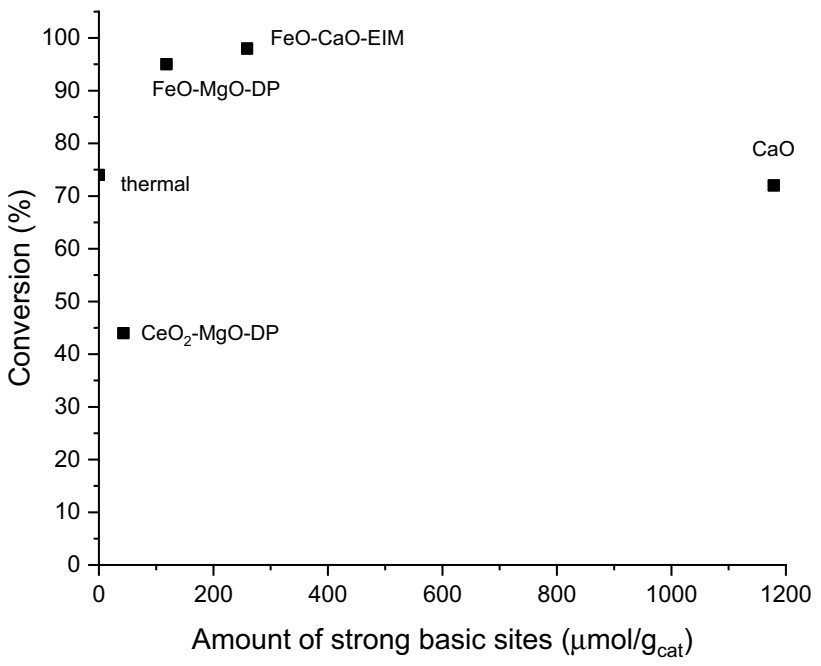

Fig. 8 Conversion of valeraldehyde after $1 \mathrm{~h}$. The initial valeraldehyde concentration was $0.53 \mathrm{~mol} / 1$ in cyclohexane. The experiments were performed at $130{ }^{\circ} \mathrm{C}$ under argon flow

an isomer of the desired 2-pentyl-2-cyclopent-1-one were formed. This result clearly shows that valeraldehyde selfcondensation does not require any catalyst under the studied conditions. In addition the isomerization of the desired product, 2-pentylidenecyclopentanone can occur, especially at relatively high temperatures due to the fact that 2-cyclopent-1-one 5 is thermodynamically more stable than 4 due

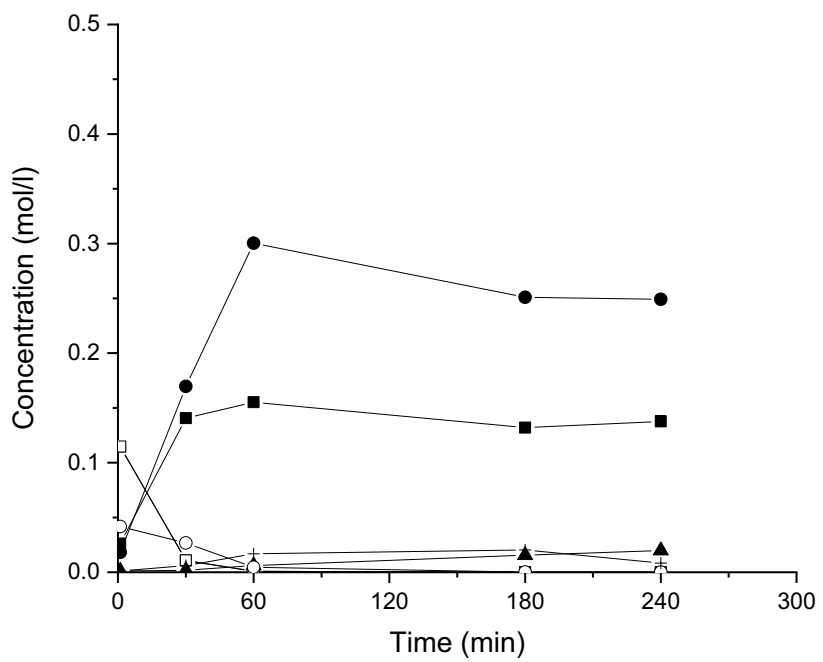

Fig. 9 Concentration of valeraldehyde and its self- and cross-condensation products as a function of time in valeraldehyde crosscondensation with cyclopentanone over $\mathrm{FeO}-\mathrm{CaO}-\mathrm{EIM}$. The initial valeraldehyde concentration was $0.53 \mathrm{~mol} / \mathrm{l}$ in cyclohexane. The experiments were performed at $130{ }^{\circ} \mathrm{C}$ under argon flow. Symbols: valeraldehyde (white square), 2-pentylidenecyclopentanone $\mathbf{4}$ (black circle), 2-pentyl-2-cyclopent-1-one 5 (white circle), 2-propyl-3-hydroxyheptanal $(+)$ 1, 2-propylhept-2-enal (black up-pointing triangle) $\mathbf{2}$ and 1-hydroxy-2-pentylcyclopentanone (black square) $\mathbf{3}$ 


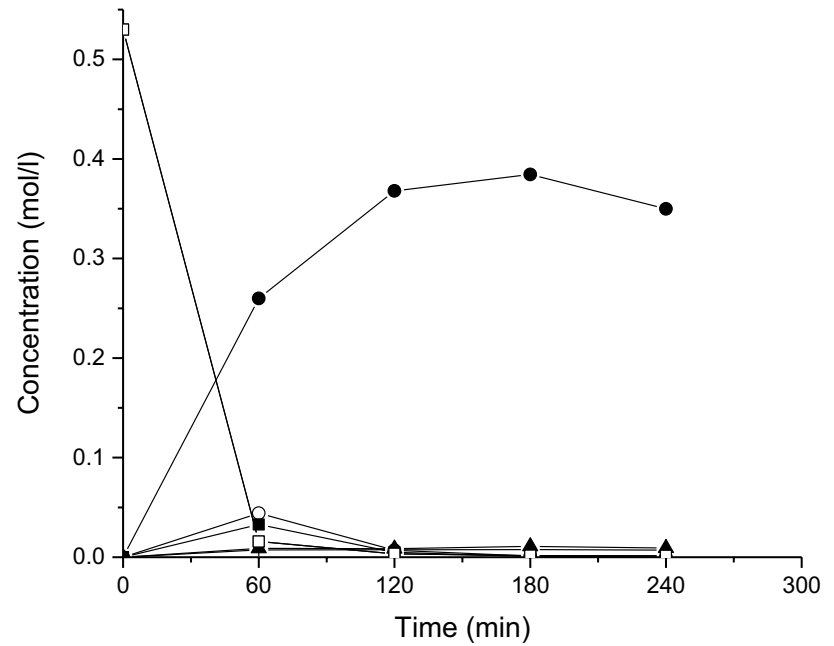

Fig. 10 Concentration of valeraldehyde and its self- and crosscondensation products as a function of time in valeraldehyde crosscondensation with cyclopentanone over $\mathrm{FeO}-\mathrm{MgO}-\mathrm{DP}$. The initial valeraldehyde concentration was $0.53 \mathrm{~mol} / \mathrm{l}$ in cyclohexane. The experiments were performed at $130{ }^{\circ} \mathrm{C}$ under argon flow. Symbols: valeraldehyde (white square), 2-pentylidenecyclopentanone 4 (black circle), 2-pentyl-2-cyclopent-1-one $\mathbf{5}$ (white circle), 2-propyl-3-hydroxyheptanal (+) 1, 2-propylhept-2-enal (black up-pointing triangle) 2 and 1-hydroxy-2-pentylcyclopentanone (black square) 3

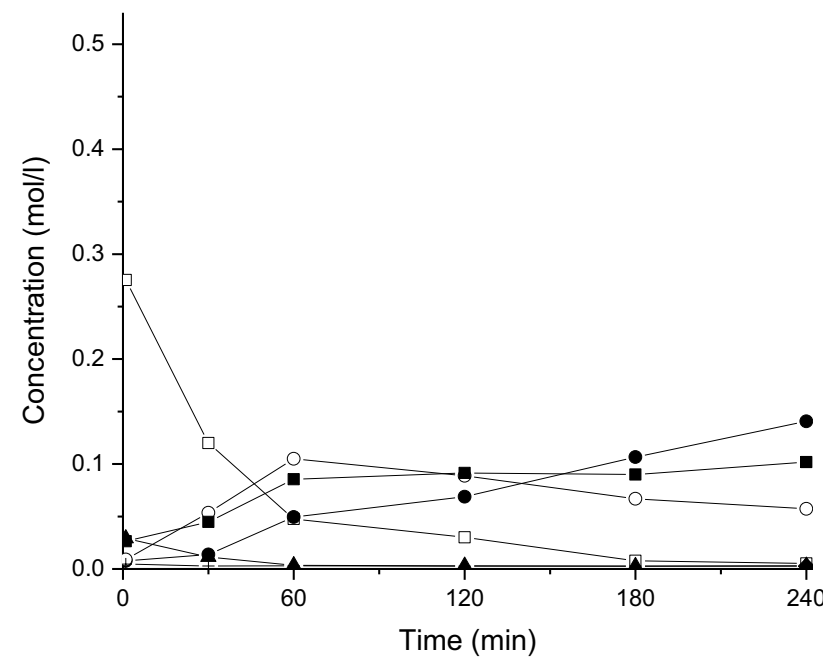

Fig. 11 Concentration of valeraldehyde and its self- and crosscondensation products as a function of time in valeraldehyde crosscondensation with cyclopentanone over $\mathrm{CeO}_{2}-\mathrm{MgO}-\mathrm{DP}$. The initial valeraldehyde concentration was $0.53 \mathrm{~mol} / 1 \mathrm{l}$ in cyclohexane. The experiments were performed at $130{ }^{\circ} \mathrm{C}$ under argon flow. Symbols: valeraldehyde (white square), 2-pentylidenecyclopentanone 4 (black circle), 2-pentyl-2-cyclopent-1-one $\mathbf{5}$ (white circle), 2-propyl-3-hydroxyheptanal (+) 1, 2-propylhept-2-enal (black up-pointing triangle) 2 and 1-hydroxy-2-pentylcyclopentanone (black square) $\mathbf{3}$

to the presence of a conjugated double bonds, i.e. a carbonyl bond and a cyclic olefinic bond and high temperatures favor isomerization [2]. The sum of the reactant and product

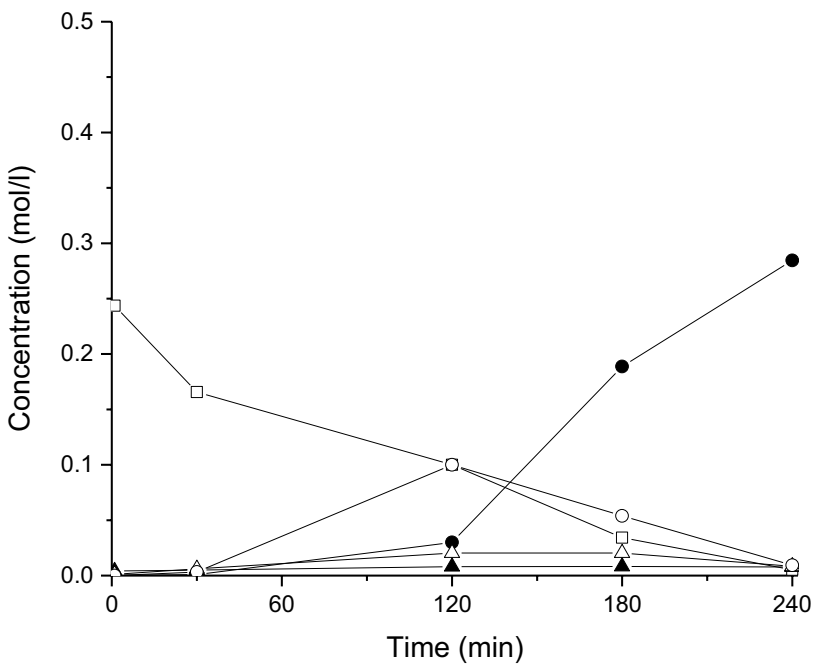

Fig. 12 Concentration of valeraldehyde and its self- and crosscondensation products as a function of time in valeraldehyde crosscondensation with cyclopentanone over $\mathrm{CaO}$. The initial valeraldehyde concentration was $0.53 \mathrm{~mol} / 1$ in cyclohexane. The experiments were performed at $130{ }^{\circ} \mathrm{C}$ under argon flow. Symbols: valeraldehyde (white square), 2-pentylidenecyclopentanone 4 (black circle), 2-pentyl-2-cyclopent-1-one $\mathbf{5}$ (white circle), 2-propyl-3-hydroxyheptanal (+) 1, 2-propylhept-2-enal (black up-pointing triangle) 2 and 1-hydroxy-2-pentylcyclopentanone (black square) 3

concentrations was close to $100 \%$. Since thermal aldol condensation of valeraldehyde-cyclopentanone showed promising results, it was worth to investigate the performance of catalysts at the same conditions. Valeraldehyde self-condensation is a thermodynamically feasible reaction even if approximate calculations of the Gibbs free energy for formation of the intermediate 2-propyl-3-hydroxyheptanal, gave a positive value.

Catalytic cross-condensation of valeraldehyde with cylopentanone was investigated over two different $\mathrm{FeO}$ catalysts supported on $\mathrm{MgO}$ and $\mathrm{CaO}$ as well as $\mathrm{CaO}$ per se and $\mathrm{CeO}_{2}-\mathrm{MgO}-\mathrm{DP}$ (Table 6; Figs. 7, 8, 9, 10, 11, 12). The initial rates for valeraldehyde transformation decreased in the following order: $\mathrm{FeO}-\mathrm{MgO}-\mathrm{DP}>\mathrm{CeO}_{2}-\mathrm{MgO}-\mathrm{DP}>\mathrm{FeO}-\mathrm{CaO}-\mathrm{EIM}>\mathrm{CaO}$ (Table 6). This order shows that the catalysts with the lowest basicity exhibited also the lowest initial valeraldehyde transformation rate, apart from a highly basic $\mathrm{CaO}$. This could be explained by initial poisoning of $\mathrm{CaO}$ by traces of water and $\mathrm{CO}_{2}$ despite drying over night at $100{ }^{\circ} \mathrm{C}$ in an oven. Based on the literature [39] dehydration of the basic catalysts is required to remove adsorbed water and $\mathrm{CO}_{2}$. It is believed that this type of poisoning could easily occur for very basic $\mathrm{CaO}$ even in few minutes when loading the catalyst into the reactor. In addition when comparing the converted amounts of valeraldehyde after 120 min obtained with $\mathrm{CaO}$ (Fig. 12) and FeO-CaO-EIM (Fig. 11), it can be 
seen that for neat $\mathrm{CaO}$ the conversion was only $83 \%$ compared with $99 \%$ obtained by $\mathrm{FeO}-\mathrm{CaO}-$ EIM showing also that addition of just $10 \mathrm{wt} \% \mathrm{FeO}$ increased activity of $\mathrm{CaO}$.

Comparison of conversion levels over different catalysts shows that $\mathrm{CaO}, \mathrm{FeO}-\mathrm{CaO}-\mathrm{EIM}$ and $\mathrm{CeO}_{2}-\mathrm{MgO}-\mathrm{DP}$ with strong basicity efficiently converted valeraldehyde. The conversion levels increased also with the increasing amount of strong basic sites (Fig. 8). The sums of the liquid phase products determined by GC (GCLPA) were high with $\mathrm{FeO}-\mathrm{MgO}-\mathrm{DP}$ and $\mathrm{FeO}-\mathrm{CaO}-\mathrm{EIM}$, whereas $\mathrm{CaO}$ despite its high basicity exhibited a lower sum of reactant and product masses determined by GC analysis of the liquid phase.

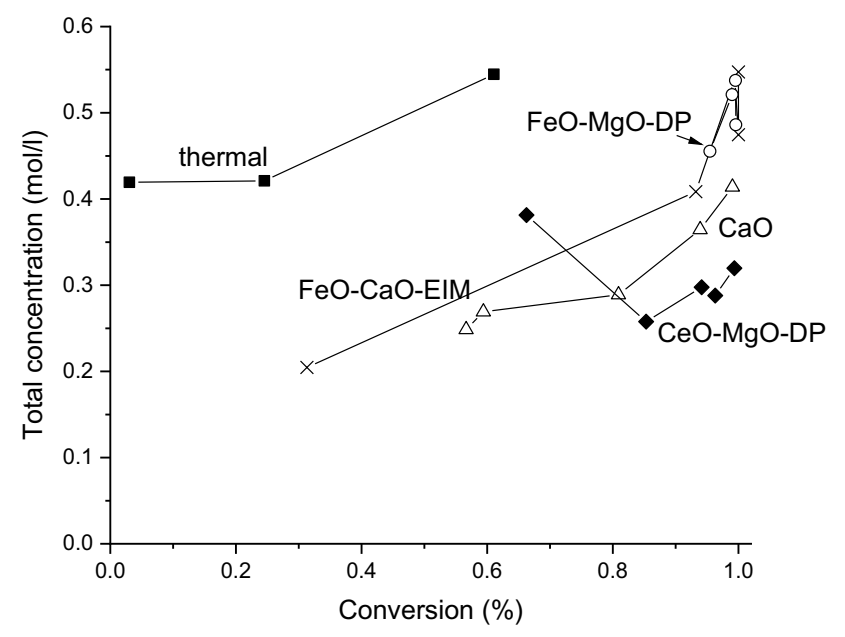

Fig. 13 A comparison of the total concentration, i.e. the sum of reactant and product concentrations from valeraldehyde self- and crosscondensation in the liquid phase, which are visible in GC analysis, as a function of conversion. The initial valeraldehyde concentration was $0.53 \mathrm{~mol} / \mathrm{l}$ in cyclohexane. The experiments were performed at $130{ }^{\circ} \mathrm{C}$ under argon flow
These results may be related to formation of oligomers, in the latter case not visible in GC.

A comparison of the total concentration, i.e. the sum of the reactant and product concentrations from valeraldehyde self- and cross-condensation in the liquid phase, which are visible in GC analysis, as a function of conversion is shown in Fig. 13. The initial concentration of valeraldehyde was $0.53 \mathrm{~mol} / \mathrm{l}$ and as it can be seen the highest total concentration is obtained in the absence of catalyst being after $3 \mathrm{~h}$. In addition the total concentration increased with increasing conversion for those catalysts which were relatively good for catalyzing the formation of the desired product 4 , i.e. $\mathrm{FeO}-\mathrm{CaO}-\mathrm{EIM}, \mathrm{FeO}-\mathrm{MgO}-\mathrm{DP}$ and $\mathrm{CaO}$. It can also be seen from Fig. 13 that the lowest total concentrations were obtained with $\mathrm{CeO}-\mathrm{MgO}-\mathrm{DP}$ and $\mathrm{FeO}-\mathrm{CaO}-\mathrm{DP}$. The latter catalyst exhibited a very high concentration of acid sites most probably promoting oligomerisation.

Selectivity in the cross-condensation of valeraldehyde with cyclopentanone in comparison with valeraldehyde selfcondensation can be evaluated by considering the ratio of the cross-condensation to valeraldehyde self-condensation products for thermal and catalytic experiments (Table 6) showing that this ratio was very low for the thermal reaction and reasonably high for catalytic experiments with basic catalysts. The yields of the desired product $\mathbf{4}$ and self-condensation product of valeraldehyde 2 over different catalysts after $4 \mathrm{~h}$ reaction illustrate that the highest yield of the desired product was obtained over $\mathrm{FeO}-\mathrm{MgO}-\mathrm{DP}$ followed by $\mathrm{CaO}$ and FeO-CaO-EIM (Table 6; Figs. 9, 10, 12). Repeatability in the cross condensation reactions was adequate showing for $\mathrm{FeO}-\mathrm{CaO}-\mathrm{EIM}$ catalyst minor deviations in the yield of the desired product $4,42 \pm 3 \%$. All these catalysts exhibited strong basicity (Table 3). Intensive 2-propylhept-2-enal formation occurred only in the absence of heterogeneous catalysts. This result is in accordance with [1] where it was

Table 6 Results from valeraldehyde cyclopentanone cross condensation in thermal and catalytic experiments using cyclopentanone both as a solvent and reactant at $130{ }^{\circ} \mathrm{C}$ under argon flow

\begin{tabular}{|c|c|c|c|c|c|c|c|c|c|}
\hline Entry & Catalyst & $\begin{array}{l}\text { GCLPA (mol- } \\
\% \text { ) after } 4 \mathrm{~h}\end{array}$ & $\begin{array}{l}\text { Init. rate } \\
(\mathrm{mmol} / \mathrm{min} \\
\left.\mathrm{g}_{\text {cat }}\right)\end{array}$ & $\begin{array}{l}\text { Conversion } \\
\text { (\%) after } 4 \mathrm{~h}\end{array}$ & $\frac{\sum c_{0, V A}}{\sum c_{0, V A-C P}} \mathrm{~b}$ & $\begin{array}{l}\text { Yield of } 4 \\
(\mathrm{~mol}-\%)\end{array}$ & $\begin{array}{l}\text { Yield of } 2 \\
(\mathrm{~mol}-\%)\end{array}$ & $\begin{array}{l}\text { Yield of } 5 \\
(\mathrm{~mol}-\%)\end{array}$ & $\begin{array}{l}\text { Ratio } \\
\text { between } \mathbf{4 / 2} \\
\text { after } 4 \mathrm{~h}\end{array}$ \\
\hline 1 & Thermal & $40^{\mathrm{a}}$ & n.d & $95^{\mathrm{a}}$ & 2.3 & 1 & 28 & 11 & 0.03 \\
\hline 2 & $\mathrm{CeO}_{2}-\mathrm{MgO}-\mathrm{DP}$ & 60 & 0.17 & 99 & 0.54 & 26 & $<1$ & 11 & 47 \\
\hline 3 & $\mathrm{CaO}$ & 77 & 0.08 & 100 & 0.08 & 53 & 2 & 19 & 27 \\
\hline 4 & $\mathrm{FeO}-\mathrm{CaO}-\mathrm{EIM}$ & 100 & 0.11 & 100 & 0.01 & 45 & 3 & 25 & 15 \\
\hline 5 & $\mathrm{FeO}-\mathrm{MgO}-\mathrm{DP}$ & 92 & 0.27 & 95 & 0.07 & 66 & 2 & 19 & 33 \\
\hline
\end{tabular}

2-pentylidenecyclopentanone 4, 2-propylhept-2-enal 2, isomer of 2-pentylidenecyclopentanone 5. GCLPA denotes the sum of the concentrations of valeraldehyde and its self- and cross condensation products visible in GC analysis. The initial valeraldehyde concentration was 0.53 mol/l, cyclopentanone was used both as a reactant and solvent

a $3 \mathrm{~h}$

$\mathrm{b} \frac{\sum c_{0, V A}}{\sum c_{0, V A-C P}}$ denotes the initial ratio of the sum of the concentration VA self-condensation products/sum of the concentration of VA-CP cross condensation products 


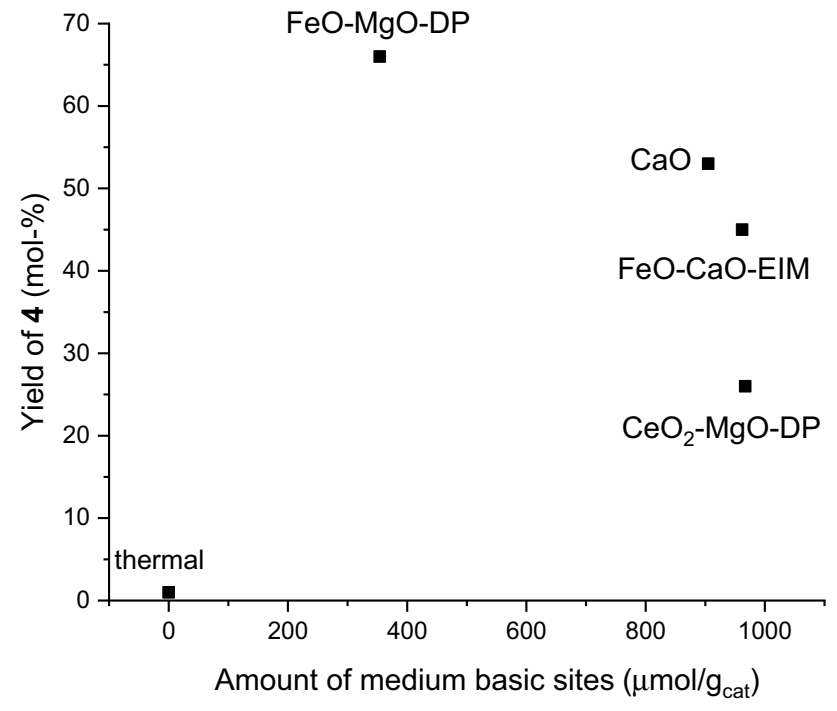

Fig. 14 The yield of 2-pentylidenecyclopentanone $4 \mathrm{~h}$ as a function of medium strong basic sites in the catalyst

concluded that formation of 2-propylhept-2-enal was the lowest with $\mathrm{MgO}$ and $\mathrm{Al}_{2} \mathrm{O}_{3}-\mathrm{SiO}_{2}$, having acid-base site pairs.

The isomer of the desired product (e.g. compound 5) was formed mainly over $\mathrm{FeO}-\mathrm{MgO}-\mathrm{DP}$ as well as over $\mathrm{CaO}$ and $\mathrm{FeO}-\mathrm{CaO}-\mathrm{EIM}$ showing that double bond migration occurs not only on acidic, but also on basic sites. According to ammonia TPD FeO-CaO-EIM, in which the iron containing phase is $\mathrm{Ca}_{2} \mathrm{Fe}_{2} \mathrm{O}_{5}$, is also acidic promoting formation of the desired product isomer (Table 3; Fig. 9). When acidity of $\mathrm{CeO}_{2}-\mathrm{MgO}-\mathrm{DP}$ was lower, subsequently lower amounts of 2-hydroxy-2-pentylcyclopentanone were formed (Table 6, entry 2) compared to $\mathrm{FeO}-\mathrm{CaO}-\mathrm{EIM}$ (Table 6, entry 4).

Noteworthy is also that valeraldehyde self-condensation to form 2-propylhept-2-enal was concluded to be more acid catalyzed, when it was investigated [11] over a more acidic $\mathrm{TiO}_{2}$ catalyst. In this work, however, self-condensation with a relatively highly acidic $\mathrm{FeO}-\mathrm{CaO}-\mathrm{EIM}$ was not able to produce high amounts of 2-propylhept-2-enal. In addition, activity of $\mathrm{FeO}-\mathrm{CaO}-\mathrm{EIM}$ catalyst was decreased after 60 min since dehydration of 2-hydroxy-2-pentylcyclopentanone to the desired product was inhibited (Fig. 9).

Only traces of 2,5-dipentylidene cyclopentanone 7 were formed despite its negative Gibbs free energy. This result indicates that consecutive condensation was retarded. Furthermore, all valeraldehyde has reacted after $120 \mathrm{~min}$ over $\mathrm{FeO}-\mathrm{MgO}-\mathrm{DP}$, when the concentration of 2-pentylidenecyclopentanone was high indicating that valeraldehyde reacted already to some heavy compounds before that, since the GCLPA was $92 \%$.

Esterification of valeraldehyde via the Tischenko reaction forming pentyl valerate $\mathbf{8}$ was not observed in this work in line with the thermodynamic calculations, showing that such reaction is unfeasible in the studied temperature range.

Comparison of the yield of 2-pentylidenecyclopentanone 2 obtained by all catalysts at $4 \mathrm{~h}$ reaction time (Fig. 14) shows that an optimum amount of the largest total amount of basic sites is required for production of cross condensation products with the highest yield of $\mathbf{2}$ generated over FeO-MgO-DP. In [1] the conclusion was reached that either strongly acidic (e.g. $\mathrm{Al}_{2} \mathrm{O}_{3}-\mathrm{SiO}_{2}$ ) or base catalysts, (e.g. $\mathrm{MgO}$ ) are required, rather than bifunctional catalysts.

\section{Conclusions}

Ce-, Fe-modified $\mathrm{CaO}, \mathrm{CeO}_{2}$ and $\mathrm{MgO}$ base catalysts were successfully synthesized using deposition-precipitation (DP) and evaporation impregnation methods (EIM). The physicochemical characterization of the catalysts using TPD- $\mathrm{CO}_{2}$ showed the presence of the largest total amount of basic sites after $\mathrm{CaO}$ in $\mathrm{FeO}-\mathrm{CaO}-\mathrm{EIM}(1234 \mu \mathrm{mol} / \mathrm{g})$ followed by $\mathrm{CeO}-\mathrm{MgO}-\mathrm{DP}(1087 \mu \mathrm{mol} / \mathrm{g})$ catalyst. $\mathrm{FeO}-\mathrm{CaO}-\mathrm{EIM}$ catalyst resulted in the highest conversion $(100 \%)$ of valeraldehyde during cyclopentanone cross-condensation with valeraldehyde. $\mathrm{FeO}-\mathrm{MgO}-\mathrm{DP}$ catalyst synthesized using the deposition precipitation method afforded the highest yield of the desired product 2-pentylidenecyclopentanone (66\%), clearly indicating that the method of catalyst synthesis has a tremendous influence on conversion and selectivity to the desired products. Correlation of valeraldehyde conversion with the amount of medium strong basic sites revealed that these sites affect the aldol condensation reaction.

Acknowledgments Open access funding provided by Abo Akademi University (ABO).

Open Access This article is distributed under the terms of the Creative Commons Attribution 4.0 International License (http://creativeco mmons.org/licenses/by/4.0/), which permits unrestricted use, distribution, and reproduction in any medium, provided you give appropriate credit to the original author(s) and the source, provide a link to the Creative Commons license, and indicate if changes were made.

\section{References}

1. Hasni M, Prado G, Rouchaud J, Grange P, Devillers M, Delsarte S (2006) J Mol Catal A Chem 247:116-123

2. Xu J, Cao Y, Ma Q, Peng X (2013) Asian J Chem 25:3847-3849

3. Xie J, Zhang L, Zhang X, Han P, Xie J, Pan L, Zou DR, Liu SH, Zou JJ (2018) Sust Energy Fuels 2:1863-1869

4. Deng Q, Xu J, Han P, Pan L, Wang L, Zhang X, Zou JJ (2016) Fuel Proc Tech 148:361-366

5. Kwong TL, Yung KF (2015) RSC Adv 5:83748-83756

6. Mahrwald R, Schick H (1990) Synthesis 7:592-595

7. Han Z, Yorimitsu H, Hideki S, Hiroshi S, Oshima K (2000) Tetrahedron Lett 41(22):4415-4418C 
8. Martin A (1998) US patent 5776884

9. Fujisawa H, Kondou Y, US patent (2005) $2005 / 0009928$ A1

10. Liang D, Li G, Liu Y, Wu J, Zhang X (2016) Catal Comm 81:33-36

11. Deng Q, Nie G, Pan L, Zou J-J, Zhang X, Wang L (2015) Green Chem 17:4473-4481

12. Poncet AF (1982) FR patent, 2500477

13. Zhao L, An H, Zhao X, Wang Y (2016) Ind Eng Chem Res 55:12326-12333

14. Tang Z, Zhou Y, Feng Y (2004) Appl Catal A Gen 273:171-176

15. Vrbkova E, Tisler Z, Vyskocilova E, Kadlec D, Cerveny L (2018) Chem Technol Biotech 93:166-173

16. Vit Z, Nondek L, Malik J (1982) Collect Czech Chem Commun 47:2235-2245

17. Vrbkova E, Vyskocilova E, Krupka J, Cerveny L (2016) Progr React Kinet Mech 41:289-300

18. MAUD. http://www.ing.unitn.it/ maud/. Accessed 8 Dec 2018

19. Powder Diffraction File 2 (PDF-2), sets 1-46, 1996 release, International Centre for Diffraction Data (ICDD)

20. Inorganic Crystal Structure Database (ICSD) http://www.fiz-karls ruhe.de/icsd.html. Accessed 8 Dec 2018

21. Crystallography Open Database http://www.crystallography.net/ cod/index.php. Accessed 8 Dec 2018

22. Chesnokov B, Bazhenova L (1985) Zap Vses Mineral O-va 114: 195-196.20. Germany, ICDD Grant-in-Aid

23. Yang S, Zhang X, Chen L, Sun L, Xie X, Zhao B (2017) J Anal Appl Phys 125:1-8

24. Morris MC, McMurdie HF, Evans EH, Paretzkin B, Parker HS, Pyrros NP (1983) Standard X-ray Diffraction Powder Patterns, NBS Monograph 25 - Section 20, National Bureau of Standards, p 38

25. Swanson HE, Tatge E (1953) Natl Bur Stand (US) Circ 539(I):15

26. Swanson HE, Tatge E (1953) Natl Bur Stand (US) Circ 539(I):15.24
27. Morris MC, McMurdie HF, Evans EH, Paretzkin B, Parker HS, Panagiotopoulos NC (1981) Standard X-ray Diffraction Powder Patterns, NBS Monograph 25 - Section 18, National Bureau of Standards, p 37

28. Kern A, Doetzer R, Eysel W (1993) Mineralogisch-Petrographisches Inst., Univ. Heidelberg. Germany, ICDD Grant-in-Aid, (1993)

29. Yang J, Li N, Li S, Wang W, Wang A, Wang X, Cong Y, Zhang T (2014) Green Chem 16:4879-4884

30. Ye L, Lin H, Zhou H, Yuan Y (2010) J Phys Chem C 114:19753-19760

31. Ferretto L, Glisenti A (2002) J Mol Catal A: Chem 187:119-128

32. Miles WH, Nutaitis CF, Anderton CA (1996) Chem Educ 73:272

33. Dumitriu E, Hulea V, Fechete I, Auroux A, Lacaze JF, Guimon C (2001) Micropor Mesop Mater 43:341-359

34. Nemansky MW, Abbott MM, Van Ness HC (1975) Basic engineering thermodynamics. McGraw-Hill, New York

35. Poling BE, Prausnitz JM, O'Connell JP (2004) The properties of gases and liquids, 5th edn. McGraw-Hill, New York

36. Joback KG (1984) A unified approach to physical property estimation using multivariate statistical techniques, Thesis SM, Department of Chemical Engineering, Massachusetts Institute of Technology, Cambridge, MA

37. Joback KG, Reid RC (1987) Chem Eng Comm 57:233-243

38. Heinz AS, Gonzales JE, Fink MJ, Mitchell BS (2008) J Mol Catal A Chem 304:117-120

39. Hattori H (1995) Chem Rev 95:537-558

Publisher's Note Springer Nature remains neutral with regard to jurisdictional claims in published maps and institutional affiliations. 